\title{
RECURSOS DIDÁTICOS: CONCEITO E IMPLICAÇÕES PEDAGÓGICAS NO PROCESSO DE ENSINO- APRENDIZAGEM
}

\author{
Tuesla Bezerra Santos ${ }^{1}$ \\ Karina de Oliveira Lima ${ }^{2}$ \\ Kleber Kroll de Azevedo Silva ${ }^{3}$
}

\begin{abstract}
RESUMO
O presente tem como objetivo averiguar, numa perspectiva comparativa, o uso de diferentes recursos didáticos e os impactos no processo de ensino-aprendizagem em uma turma do ensino médio integrado do Instituto Federal de Educação, Ciência e Tecnologia-IFRN, Campus Ipanguaçu, na disciplina de Matemática. A pesquisa se caracteriza como um estudo exploratório de natureza qualitativa, no qual a construção dos dados ocorreu por meio da aplicação de questionários direcionados aos alunos, de entrevistas semiestruturadas junto à professora titular e de observações in loco. Desse modo, observa-se que as aplicações dos diferentes recursos didáticos, tanto os convencionais quanto os que adotam as novas tecnologias, tiveram avaliações similares, possuem benefícios e dificuldades característicos e permitem múltiplas possibilidades no processo de ensino-aprendizagem. Assim, pode-se concluir que a utilização de diferentes recursos de forma adequada pelo professor pode trazer melhorias do ensino e da aprendizagem.
\end{abstract}

Palavras-chave: Metodologia de Ensino. Recursos Didáticos. Ensino Híbrido.

\section{INTRODUÇÃO}

Tratar sobre metodologias e recursos didáticos requer uma contextualização desses elementos, que constituem a prática educativa escolar, articulada às concepções de conhecimento, desenvolvimento e aprendizagem que as engendram, pois, abordar a técnica desarticulada das dimensões do ensino, é assumir o risco de cair em mero formalismo, repetição e reprodução acrítica do fazer docente (VEIGA, 2012). Assim, antes de adentramos, especificamente, no tema desse capítulo, apresentaremos nossas concepções sobre conhecimento, desenvolvimento e ensino-aprendizagem escolar.

Adotamos as concepções de conhecimento, desenvolvimento e aprendizagem escolar ancoradas na abordagem sócio-histórica, a qual tem como precursores um grupo de estudiosos russos liderados por Lev Semyonovich Vygotsky.

\footnotetext{
${ }^{1}$ Licenciada em Informática pelo Instituto Federal de Educação, Ciência e Tecnologia do Rio Grande do Norte. Email: tuesla.santos12@gmail.com

2 Mestra e Doutoranda em Educação pela Universidade Federal do Rio Grande do Norte. E-mail: karina.lima@ifrn.edu.br

3 Mestre em Ciência da Computação pela Universidade do Estado do Rio Grande do Norte. E-mail: kleber.kroll@ifrn.edu.br
} 
Originariamente, a palavra "aprender" vem do latim aprehendere e significa agarrar, pegar, apoderar-se de algo. Ao longo do tempo, esse conceito foi ampliado, ora dando enfoque ao papel do professor, entendido como transmissor do conhecimento, ora como facilitador do processo de ensino-aprendizagem e o aluno seria o sujeito ativo desse processo. Com os estudos de Vygotsky e colaboradores (1994), compreende-se que o aluno não é apenas passivo nem ativo; ele é interativo. Essa mudança epistemológica sobre o aprender, ensinar e o conhecimento traz implicações para a educação escolar. Nisso, a condução do processo, a definição e operacionalização das situações de ensino-aprendizagens são variáveis determinantes para os processos de ensinar e aprender.

Vygotsky atribui às situações de aprendizagem, principalmente, as situações de mediação, que promovem a aprendizagem, elemento fundamental para o desenvolvimento humano e adverte que nem toda situação de ensino promove a aprendizagem. Nesse sentido, acrescentamos que a utilização de determinados recursos, por si só, não garante a aprendizagem. Refletir sobre as variáveis que constituem a adequação dos usos dos recursos é necessário, principalmente, no atual contexto educacional permeado por uma multiplicidade de recursos disponibilizados aos professores.

Assim, é de suma importância que o professor mobilize saberes da ciência da educação e que as tomadas de decisões acerca das escolhas metodológicas tenham como elementos basilares os conhecimentos subjacentes ao métier docente.

De acordo com Libâneo (2015), fazem parte da metodologia a articulação com os objetivos e conteúdo de ensino e a utilização de instrumentos e materiais didáticos. Assim, esses elementos são determinantes na metodologia a ser adotada pelo docente.

Para Veiga (2012, p.8):

As técnicas de ensino têm um caráter instrumental e intermedeiam as relações entre professor e aluno, e entre aluno e aluno. Isso significa afirmar que as são mediações, ou condições necessárias e favoráveis, mas não suficientes do processo didático.

$\mathrm{Na}$ atualidade, as transformações e evoluções dos materiais e instrumentos tecnológicos têm mudado as perspectivas metodológicas convencionais, tanto o ensino presencial quanto o ensino a distância (EaD).

Nesta perspectiva, privilegiamos como objeto de estudo o uso de recursos didáticos e definimos como objetivo da pesquisa averiguar, numa perspectiva comparativa, o uso de 
diferentes recursos de ensino e análise comparativa das perspectivas dos alunos de uma turma do ensino médio integrado do IFRN, Campus Ipanguaçu, na disciplina de Matemática.

Para a construção deste trabalho foi realizado um estudo experimental como estratégia de investigação, no qual foram utilizadas como técnicas metodológicas: aplicação de questionários para a construção dos dados da pesquisa, por meio do público participante (professora e alunos), e observações e estudo, que construíram os elementos primordiais na elaboração dos pressupostos que deram rumo à construção da metodologia da pesquisa.

\section{CAMINHOS PERCORRIDOS: CONSTRUINDO A METODOLOGIA DE PESQUISA}

A pesquisa foi realizada junto a uma professora titular da disciplina de Matemática e os seus alunos das turmas dos $2^{\circ}$ anos, vespertino, do Curso Técnico Integrado em Informática do Instituto Federal de Educação, Ciência e Tecnologia do Rio Grande do Norte (IFRN) - Campus Ipanguaçu, Rio Grande do Norte, Brasil, no segundo semestre de 2017.

Para a elaboração deste estudo foi utilizado como método de pesquisa o estudo exploratório baseado na abordagem qualitativa em educação. Sobre esse tipo de pesquisa, Gil apud Gerhardt e Silveira (2009, p. 35) afirmam: "Este tipo de pesquisa tem como objetivo proporcionar maior familiaridade com o problema, com vistas a torná-lo mais explícito ou a construir hipóteses".

Como instrumento para a construção dos dados da pesquisa, aplicou-se um questionário com questões abertas e fechadas junto a 52 alunos matriculados nas turmas mencionadas, e estes foram perguntados sobre a percepção que tiveram diante dos diferentes recursos didáticos (quadro/lousa, apresentação eletrônica, videoaulas e software educativo) no processo de ensinoaprendizagem de Matemática em um curso do ensino médio. Os questionários foram aplicados ao final das aulas em que o docente havia adotado um dos recursos didáticos citados. O questionário, segundo Gil (1999, p.128), pode ser definido:

[...] como a técnica de investigação composta por um número mais ou menos elevado de questões apresentadas por escrito às pessoas, tendo por objetivo o conhecimento de opiniões, crenças, sentimentos, interesses, expectativas, situações vivenciadas etc.

Adotou-se também o método de entrevistas semiestruturadas realizadas com a docente titular da disciplina de Matemática da turma observada, que tiveram como foco central a obtenção de informações que compuseram a construção dos dados referentes à utilização, vantagens e desvantagens sobre o uso de cada recurso didático utilizado pela docente. Essas entrevistas foram realizadas de duas em duas, sendo a primeira sobre quadro/lousa e videoaula, e a segunda sobre 
apresentação eletrônica e software educativo. Segundo Ketele e Roegies (1996 apud Morgado 2012, p.72), a entrevista é um:

[...] método de recolha de informação que consiste em conversas orais, individuais ou em grupo, com várias pessoas selecionadas cuidadosamente, a fim de obter informações sobre factos ou representações, cujo grau de pertinência, validade e fiabilidade é analisado na perspectiva dos objetivos de recolha de informação.

$\mathrm{Na}$ pesquisa, a técnica de observação traz ao pesquisador elementos próprios de determinado conjunto de pessoas, objetivando identificar o modo de se relacionar entre si de acordo com certa circunstância. Partindo dessa ideia, Gerhardt e Silveira (2009, p. 74) definem a observação como:

Uma técnica que faz uso dos sentidos para a apreensão de determinados aspectos da realidade. Ela consiste em ver, ouvir e examinar os fatos, os fenômenos que se pretende investigar. A técnica da observação desempenha importante papel no contexto da descoberta e obriga o investigador a ter um contato mais próximo com o objeto de estudo.

Os dados construídos por meio das observações compuseram, juntamente aos dados referentes aos questionários que foram aplicados aos alunos e as entrevistas com a docente, os resultados dessa pesquisa.

\section{OS RECURSOS DIDÁTICOS UTILIZADOS NO PROCESSO DE ENSINO- APRENDIZAGEM}

O que usualmente denominamos como recursos didáticos são os materiais mobilizados pelo fazer docente para mediar e garantir as melhores condições para operacionalizar a prática docente, ou seja, constituem tecnologias educacionais. O conceito de tecnologia educacional possui duas dimensões distintas em relação à função que possui na construção dos conhecimentos, podendo assim, ser definida por Fidalgo \& Machado (2000, p. 20) como:

[...] aplicação sistemática de conhecimentos científicos e tecnológicos à solução de problemas educacionais ou como teorias e estudos específicos sobre o desenvolvimento e emprego de ferramentas, máquinas e procedimentos técnicos, em geral, em educação.

A união entre métodos, técnicas e recursos didáticos compõem as tecnologias educativas. Isso traz para a tecnologia educacional a perspectiva de ser fundamentada como parte de um corpo de conhecimentos tecnológicos e científicos, com foco no processo de ensino-aprendizagem. 
A origem da tecnologia educacional estaria, segundo Pfromm Neto (1976), nas ciências do comportamento, principalmente na Psicologia, e nas ciências físicas e nas tecnologias associadas (física, química, engenharia elétrica etc.). Outro ponto de vista apresentado por Pfromm Neto (1976) é que a origem da tecnologia da educação está ligada aos recursos tecnológicos dedicados ao campo educativo, como também à instrução programada e as máquinas de ensinar. Para isso, o autor diz que:

\begin{abstract}
A essas duas facetas originais da tecnologia da educação devem ser acrescentadas outras [...]. Referimo-nos à análise de sistemas, à cibernética, à teoria e pesquisa em comunicação e a teoria e pesquisa em psicologia da aprendizagem (PFROMM NETO, 1976, p. 5).
\end{abstract}

Os instrumentos tecno-educativos estão na posição de auxiliares e complementadores, devotados ao bom andamento dos processos que envolvem a construção dos conhecimentos, como meios pelos quais alunos e professores se comunicam e/ou por meio do que se é adequado utilizarem-vos como ferramenta mediadora na ação didática.

Os tópicos a seguir apresentam as tecnologias utilizadas no estudo exploratório deste trabalho.

\title{
O QUADRO
}

Diante de tantas tecnologias voltadas ao ensino, a que foi mais utilizada e ainda é utilizada até hoje (em menor número) é o quadro-negro, quadro-de-giz ou simplesmente quadro que possui o significado de quadrado. Essa definição possui datação em língua portuguesa registrada a partir do ano de 1612.

Superfície lisa, plana ou ligeiramente côncava, feita de madeira ou ardósia, geralmente pintada de negro ou verde, muito usado nas escolas para sobre ela escrever-se a giz; quadro-de-giz, quadro-negro[...] (HOUAISS, 2001, 2344).

O quadro-negro e/ou o quadro-branco representam o objeto central em sala de aula, para o qual todos os alunos devem manter suas atenções voltadas, paralelo ao lado onde o professor se encontra e propõe aos alunos os ensinamentos. Essa distribuição ou organização, embora possa aparentar certa superioridade do professor e dos conteúdos em relação aos alunos, por outro lado, como apontado por Araújo (2006), promove a interação entre o professor e os alunos e triunfa com a generalização do ensino simultâneo. 
Essas tecnologias convencionais que privilegiam o uso da escrita manual são ainda muito utilizadas, tanto que é difícil pensar em uma sala de aula que não possua uma delas, tornaram-se, assim, uma tecnologia característica do ambiente de ensino.

\section{APRESENTAÇÃO ELETRÔNICA}

Uma apresentação eletrônica é um recurso de sociabilização para exposição de temas diversos e mediação de informações em contextos diversos, com múltiplas finalidades, tais como: reuniões, seminários, palestras, aulas, entre outros. Nesse contexto, Ramos, Arriada e Fiorentini (2009) escrevem que:

\footnotetext{
As apresentações de slides ocupam lugar de destaque no contexto das escolas, em geral. Uma nova textualidade muito peculiar está associada a este tipo de documento digital. Além do uso de integrado de textos, voz, música e imagens, temos também a possibilidade da animação e da leitura não linear. Todas estas características de uma produção hipermidiática são conseguidas através de uma ferramenta de edição bastante amigável (RAMOS; ARRIADA; FIORENTINI, 2009, p. 90).
}

A estrutura de uma apresentação eletrônica é composta por várias telas em formato de ficha (slides), que são exibidas sequencialmente com o auxílio de um computador. A exibição das apresentações eletrônicas, comumente, é realizada por meio de dispositivos de projeção (datashow, retroprojetor, epidiascópio, entre outros), em que a imagem real de um objeto é ampliada e projetada sobre uma tela.

Essas outras tecnologias possuem usualidade, interatividade e diversidade quanto à exibição de por meio de recursos multimídia (de imagem, som, vídeos etc.), simulação de imagem (gráficos 3D, emuladores de processos etc.) e acesso livre à navegação na Web.

\section{A VIDEOAULA}

As primeiras câmeras surgiram no mercado no ano de 1965, mas, somente a partir da década de 1980, essa mídia explodiu em quesitos de popularidade com o surgimento dos aparelhos de videocassete (VHS), e, na década de 1990, com os aparelhos com tecnologia de discos ópticos (DVD), até os anos 2000 com a popularização da internet as multimídias, principalmente o vídeo, o que vem se tornando cada vez mais presente no ensino e na aprendizagem. 
Todo o percurso histórico das videoaulas está diretamente ligado ao desenvolvimento dos recursos e metodologias adotadas no ensino a distância. Os autores Candeias e Carvalho (2016, p. 8) indicam que:

O uso dessas aulas em vídeo contempla os alunos com diferentes percepções do conteúdo, onde estas aulas são apresentadas de forma multissensorial, pois utiliza-se de vídeo, áudio e imagens, fazendo com que o aluno tenha um interesse maior pelo conteúdo, incentivando-o a pesquisar mais sobre o assunto. Dessa forma, o aluno irá sentir-se mais estimulado em aprender, diferente das aulas tradicionais que se norteiam apenas pela linguagem escrita e falada.

A videoaula possui uma estruturação peculiar divergente dos demais recursos: a possibilidade de acessar essas videoaulas e complementar, resgatar ou até construir os conhecimentos necessários a partir de aulas gravadas.

\section{SOFTWARE EDUCATIVO}

No âmbito educacional, o software se tornou o mais importante elemento para que o computador fosse inserido no processo de ensino-aprendizagem como tecnologia educativa (JUCÁ, 2006, p. 23).

Com a utilização desse recurso, os alunos têm a autonomia quanto à manipulação do meio de acesso, que, no caso do software, é o computador. Outras alternativas para inserir os softwares educativos nas salas de aula têm sido utilizadas, como a citada por Gouvêa e Pereira (2015, p. 42), quando dizem que:

Precisamos buscar meios que proporcionem o seu acesso a todas as pessoas, inclusive o celular entre os alunos de forma educativa, já que este é um meio de comunicação de mais fácil acesso e que seus aplicativos podem contribuir para aprimorar os conhecimentos já existentes.

Nesse contexto, a aprendizagem móvel se mostra promissora, já que de acordo com dados divulgados pela Agência Nacional de Telecomunicações (Anatel), a telefonia móvel registrou 240.850.681 linhas em operação em outubro de 2017. O uso do celular, principalmente pelos jovens, é uma realidade muito atual no meio educacional e também pelo motivo de que este é um dos avanços que faz parte da vida da maioria da população e dos jovens alunos. 


\section{ENSINO HÍBRIDO}

O blended learning, em livre tradução "aprendizado mesclado", ou como ficou definido em língua portuguesa pelo termo “Ensino Híbrido”. Segundo Christesen, Horn e Staker (2015), “[...] é uma combinação da nova tecnologia disruptiva com a antiga tecnologia, e representa uma inovação sustentada em relação à tecnologia anterior”. Esse modelo de ensino é denominado assim por integrar o ensino presencial ao ensino virtual, na escola e fora dela.

No ensino híbrido, o objetivo é estimular a autonomia dos alunos para que eles consigam desenvolver uma consciência de trabalho grupal e compartilharem seus novos conhecimentos adquiridos. De acordo com Bacich e Tanzi Neto (2015, p. 3):

[...]esses espaços se tornam complexos sistemas de interações entre alunoconhecimento, aluno-professor, aluno-aluno, no qual a distribuição do conhecimento não se dá apenas pelo professor, mas por todos os seus participantes com a ajuda de diferentes ferramentas digitais. Sendo assim, o Ensino Híbrido parte de uma proposta metodológica que impacta na ação no professor em situações de ensino e na ação dos estudantes em situações de aprendizagem, pois a troca entre os pares com diferentes habilidades e conhecimento se torna mais fluida e participativa.

Há integração dos acrescimentos como interação, relações interpessoais, troca de experiências e vivência em grupo presentes no ensino presencial; juntamente com as múltiplas possibilidades como autonomia e livre acesso à informação trazidas pelo ensino virtual. Tudo isso integrado pode vir a se tornar a força motriz da mudança nas formas de ensinar e aprender.

\section{DIÁLOGOS ENTRE O DESEMPENHO DOS RECURSOS DIDÁTICOS NA PERSPECTIVA DO DOCENTE E DOS ALUNOS}

Considerando os objetivos mencionados anteriormente, privilegiamos como objeto averiguar numa perspectiva comparativa o uso desses diferentes recursos de ensino (quadro/lousa, videoaula, apresentação eletrônica e software educativo) e os seus impactos no processo de ensinoaprendizagem em uma turma do ensino médio integrado.

O Quadro 1 apresenta as percepções dos discentes e da docente em relação aos maiores benefícios/vantagens da utilização dos recursos didáticos nas aulas observadas: 
Quadro1 - Benefícios/vantagens da utilização dos recursos didáticos

\begin{tabular}{|c|c|c|}
\hline RECURSOS & $\begin{array}{l}\text { TRECHOS DA FALA DA } \\
\text { PROFESSORA }\end{array}$ & FALA DOS ALUNOS \\
\hline Quadro/ lousa & $\begin{array}{l}\text { "A vantagem é talvez a questão do registro, } \\
\text { do acompanhamento do registro, com o } \\
\text { quadro você pode dar ênfase ao processo } \\
\text { passo-a-passo, fazer isso de forma cautelosa } \\
\text { com o aluno e esse tempo que muitas vezes } \\
\text { a Matemática precisa de maturidade para o } \\
\text { aluno, a compreensão do conteúdo, então o } \\
\text { quadro ajuda nesse aspecto..." }\end{array}$ & $\begin{array}{l}\text { Aluno 8: "Gostei de como foi prática, } \\
\text { enquanto a professora explicava, ela } \\
\text { escrevia e eu analisava o que ela escrevia e } \\
\text { podia, assim, tirar minhas dúvidas" } \\
\text { Aluno 9: "Acredito que em Matemática é } \\
\text { importante a utilização do quadro para } \\
\text { exemplos, resolução de contas, e utilização } \\
\text { de todo o espaço" }\end{array}$ \\
\hline Videoaula & $\begin{array}{l}\text { "[...] Eu já veja mais a videoaula como } \\
\text { contextualizar, aproveitar o vídeo para } \\
\text { trazer uma aplicação do conteúdo, pelo } \\
\text { menos é assim que eu enxergo o uso da } \\
\text { videoaula. Também trazer o ensino a } \\
\text { distância, a videoaula pode ser muito } \\
\text { importante pra questão do ensino à } \\
\text { distância, para o acompanhamento do aluno } \\
\text { a distância..." }\end{array}$ & $\begin{array}{l}\text { Aluno 2: "Traz uma diversidade no ensino, } \\
\text { saindo do "comum'. Os recursos utilizados } \\
\text { na produção do vídeo, cores, enredo, efeitos } \\
\text { e etc., chamam atenção e prendem o aluno" } \\
\text { Aluno 9: "O jeito é ótimo, porque podemos } \\
\text { aplicar o conteúdo em uma história ou } \\
\text { podemos ver por outra perspectiva" }\end{array}$ \\
\hline $\begin{array}{l}\text { Apresentação } \\
\text { eletrônica }\end{array}$ & $\begin{array}{l}\text { "Projeção de slides tem vários atributos } \\
\text { importantes no processo de ensino além da } \\
\text { ideia de fazer resumo de orientação, da aula, } \\
\text { o uso de imagens. De fato, o slide ele pode } \\
\text { trazer um aspecto bem mais atrativo do que } \\
\text { o quadro branco/lousa, porque você pode } \\
\text { utilizar um recurso que venha aliar } \\
\text { diferentes percepções: a visual, a } \\
\text { audiovisual, então o slide tem essa } \\
\text { possibilidade" }\end{array}$ & $\begin{array}{l}\text { Aluno } 02 \text { aponta que "As cores e os } \\
\text { recursos visuais que têm no slide e a } \\
\text { dinâmica de poder utilizar o quadro como se } \\
\text { fosse uma lousa digital" } \\
\text { Aluno 23: "A rapidez e a simplicidade na } \\
\text { hora da transmissão do conteúdo, sendo um } \\
\text { recurso mais dinâmico" }\end{array}$ \\
\hline $\begin{array}{l}\text { Software } \\
\text { educativo }\end{array}$ & $\begin{array}{l}\text { "[...] Com o software educativo nós nos } \\
\text { aproximamos mais da metodologia de } \\
\text { resolução de problemas na Matemática, } \\
\text { você propõe uma situação que ela vai } \\
\text { vivenciar no software e ele vai resolver com } \\
\text { o uso do software e depois retoma para que } \\
\text { nós possamos generalizar e discutir o } \\
\text { conteúdo a partir daquilo que foi vivenciado } \\
\text { pelo aluno no uso do aplicativo..." }\end{array}$ & $\begin{array}{l}\text { Aluno 36: "Achei muito interessante o uso } \\
\text { do app, pois foi prático o uso do celular para } \\
\text { uso educativo" } \\
\text { Aluno 19: "Gostei de tudo, mas em especial } \\
\text { a "liberdade" que tivemos (nos deixou } \\
\text { empolgados, pelo menos eu fiquei!)" }\end{array}$ \\
\hline
\end{tabular}

Fonte: Produzido pelos autores (2020).

Em relação às vantagens da utilização do quadro/lousa, o Aluno 8 entra em concordância com a professora quando elege o registro e ênfase dos processos, e exercitação contínua em que os registros, apontada pelo Aluno 9, como maiores benefícios da utilização do quadro/lousa, fato esse observado na aula em que no primeiro momento, a docente escreve no quadro a definição do conteúdo tratado na aula que foi "Progressão Geométrica (PG)". Pede que os alunos leiam e, em seguida, os questiona se entenderam, a partir dessa descrição escrita do termo, com o auxílio dos discentes, é construída uma fórmula Matemática (Expressão geral da PG). 
Em relação às vantagens da utilização da videoaula, a professora elege a exteriorização dos conhecimentos, que está intimamente em consonância com a análise dos alunos, como o Aluno 2, que respondeu que vê o conteúdo por uma perspectiva diferente, com outros recursos chama mais a atenção dos alunos. Já o Aluno 9 elegeu como maior vantagem do uso da videoaula a contextualização na qual os alunos puderam enxergar os conteúdos sendo aplicados, como também ver o assunto sendo explicado por outras pessoas.

A professora trouxe um jogo de xadrez para ajudar a entender o conteúdo "Soma dos termos de uma PG" e ensinou as principais características e regras desse jogo de tabuleiro, fazendo paralelo com as estratégias de guerra.

Em relação à maior vantagem da utilização da apresentação eletrônica, a docente afirma que são as inúmeras possibilidades de uso das multimídias que fazem esse recurso tão atrativo e usual. Já boa parte dos alunos, como maiores vantagens ser prático e eficiente, de acordo com o que disse o Aluno 23 que apresentação eletrônica é um dos recursos mais dinâmicos devido a sua rapidez e a simplicidade. Com uma perspectiva multissensorial do recurso similar à da professora, o Aluno 02 aponta as cores e os recursos visuais e a dinâmica dos slides podem ser comparados com as lousas digitais.

Como observado, a docente convidou os alunos a responderem na lousa, sobre a projeção que continha uma tabela a ser preenchida, algumas porcentagens de acordo com as frações, como também, outras figuras fracionadas que os discentes completaram com os valores correspondentes. Os alunos que não foram até a lousa ajudaram aos que o fizeram, ditando os resultados corretos para cada componente.

Em relação à maior vantagem da utilização do software educativo, a docente aponta a possibilidade de inovar metodologicamente, saindo das aulas expositivas e focar na resolução de problemas, possibilitando promover a interação dos alunos com os conteúdos e interagir com os alunos por meio disto, que entra em concordância com o Aluno 36 que apontou o aplicativo na aula como prático e interativo devido ao uso do celular pelos alunos. Já o Aluno 19 elegeu a liberdade que os alunos tiveram, isso pode ser motivado pelo fato de que, na sala de aula, o acesso ao sinal wi-fi é muito comprometido e os alunos tivessem que sair para acessar o site e usar o software em outros pontos da instituição com melhor sinal de internet.

Os alunos usaram o celular para acessar o app online. O projetor foi usado para mostrar aos alunos as etapas de acesso ao software educativo, no Portal da Matemática do site da OBMEP, como também, as instruções de uso da aplicação. 
É possível também que uma escolha não adequada de um desses instrumentos possa prejudicar ou dificultar o movimento de construção de determinado conhecimento.

O Quadro 2 apresenta as percepções dos discentes e da docente em relação aos maiores problemas/dificuldades da utilização dos recursos didáticos nas aulas observadas.

Quadro2 - Problemas/dificuldades da utilização dos recursos didáticos

\begin{tabular}{|c|c|c|}
\hline RECURSOS & FALA DA PROFESSORA & FALA DOS ALUNOS \\
\hline Quadro/lousa & $\begin{array}{l}\text { "O quadro quando ele tá desconectado com a turma, } \\
\text { o professor interage com o quadro, o quadro com o } \\
\text { professor e ele não tem nenhum contato com a } \\
\text { turma, esse é o maior problema..." }\end{array}$ & $\begin{array}{l}\text { Aluno 18: "O fato de ter que } \\
\text { escrever muito, e ter que prestar } \\
\text { atenção ao mesmo tempo em que } \\
\text { escrevo". } \\
\text { Aluno 16:"Só não gosta do reflexo } \\
\text { da luz na lousa, me dificulta a } \\
\text { enxergar as letras" }\end{array}$ \\
\hline Videoaula & $\begin{array}{l}\text { "Eu acho que isso até aconteceu na nossa aula, todo } \\
\text { recurso que é utilizado talvez deslocado de um } \\
\text { objetivo que é o retorno dele, a sistematização do } \\
\text { que foi assistido, fica parecendo que preencheu } \\
\text { apenas o espaço das aulas..." }\end{array}$ & $\begin{array}{l}\text { Aluno 34: "pouco dinamismo, por } \\
\text { já ser uma aula definida que não } \\
\text { permite interação" } \\
\text { Aluno } 42 \text { "A imagem do vídeo, por } \\
\text { o cabo estar quebrado, e o } \\
\text { dinamismo da aula" }\end{array}$ \\
\hline $\begin{array}{l}\text { Apresentação } \\
\text { eletrônica }\end{array}$ & $\begin{array}{l}\text { "[...] O slide, como ele está muito repetitivo em sala } \\
\text { de aula, se for apenas no sentido de palestra ele pode } \\
\text { causar o problema do desinteresse dos alunos pelo } \\
\text { slide, o que a um tempo era novidade hoje não é } \\
\text { mais, muito pelo contrário está sendo bastante } \\
\text { utilizado" }\end{array}$ & $\begin{array}{l}\text { Aluno } 39 \text { "O slide poderia ser mais } \\
\text { bem preparado" } \\
\text { Aluno } 02 \text { "O slide não era muito } \\
\text { bonito, então não me chamou muita } \\
\text { atenção" }\end{array}$ \\
\hline $\begin{array}{l}\text { Software } \\
\text { educativo }\end{array}$ & $\begin{array}{l}\text { "[...] As dificuldades sempre acontecem quando se } \\
\text { trabalha com qualquer tecnologia e as dificuldades } \\
\text { são praticamente as mesmas de acesso, algum } \\
\text { equipamento que dá algum problema. Sempre é } \\
\text { natural que no planejamento o professor tenha que } \\
\text { pensar em diversas soluções caso esses problemas } \\
\text { apareçam, isso faz parte do planejamento da aula" }\end{array}$ & $\begin{array}{l}\text { Aluno } 16 \text { "A internet estava muito } \\
\text { ruim, isso dificulta o uso do } \\
\text { aplicativo online" } \\
\text { Aluno } \mathbf{3 3} \text { "alunos dispersos pelo } \\
\text { campus" }\end{array}$ \\
\hline
\end{tabular}

Fonte: Produzido pelos autores (2020).

Quanto aos possíveis problemas/dificuldades da aula com quadro/lousa, a professora aponta que, com o uso do quadro, pode acontecer uma perda de interesse dos alunos devido à falta de interação entre docente, conteúdo e o alunado. Em consonância com a professora, o Aluno 18 aponta que a falta de interação e a dinâmica acelerada da aula afeta negativamente seu aprendizado. Já o Aluno 16, representando boa parte de seus colegas, aponta a dificuldade de enxergar os conteúdos escritos no quadro. Essas duas dificuldades ficaram evidentes em todo o 
momento da aula, já que a aula foi pausada para que os alunos pudessem escrever, como também, alguns alunos perguntavam o que havia escrito nas expressões da Progressão Geométrica.

Em relação aos maiores problemas/dificuldades da utilização da videoaula, a docente, em concordância com o Aluno 34, elegeu o pouco dinamismo que gera falta de interação. Fato percebido quando, ao início da aula, a docente comunicou que o recurso utilizado na aula seria videoaula, alguns alunos sentaram-se no chão próximo à projeção para acompanharem de perto o vídeo sobre a história do xadrez e o seu contexto com o assunto tratado da soma dos termos de uma PG. Outra dificuldade/problema foi em relação à estrutura do equipamento de projeção, que estava um pouco amarelada, motivada pelo mau contato do cabo de vídeo, o que pode ter dificultado que alguns alunos conseguissem enxergar melhor, como enfatizou o Aluno 42.

Das maiores dificuldades/desvantagens na utilização da apresentação de slides, a professora diz que o uso repetitivo faz com que esse recurso se torne desinteressante e que seja pouco interativo se não houver a exercitação e discussão dos conteúdos.

A apresentação eletrônica utilizada pela docente foi um material sobre o assunto "Porcentagem", já pronto e confeccionado por outra professora e que está disponível no site de compartilhamento de apresentações, infográficos e documentos slideshare.net. Isso motivou que o Aluno 39 e o Aluno 02 indicassem problemas na preparação, na estética, na cor e estilo dos slides, sendo que a apresentação eletrônica escolhida tinha cores fortes de fundo, letras de cor branca e alguns erros ortográficos.

Das maiores dificuldades/desvantagens encontradas na utilização do software educativo, a professora enfatizou que trabalhar com a tecnologia exige do docente que possua planos extras, pois esses recursos têm problemas inerentes às ferramentas, como de acesso e/ou equipamento.

A maior dificuldade foi o acesso à internet, sendo que a maior parte dos alunos concordou com o Aluno 16 quanto à dificuldade de acesso à internet na sala de aula. Diante desta dificuldade, inicialmente como dito pelo Aluno 33, os alunos ficaram dispersos pelo campus, (devido a atividade demandar o uso do celular e pela liberdade de eles poderem sair da sala) e saíram muitos da sala de aula, mas a docente os direcionou para que formassem os grupos e consultassem o material da última aula, que serviu como base introdutória para a atividade utilizando o software.

O Gráfico 1 representa os dados obtidos a partir das sugestões para o melhoramento, em relação às aulas com utilização dos recursos didáticos. 
Gráfico 1 - Sugestões para utilização de outros recursos didáticos

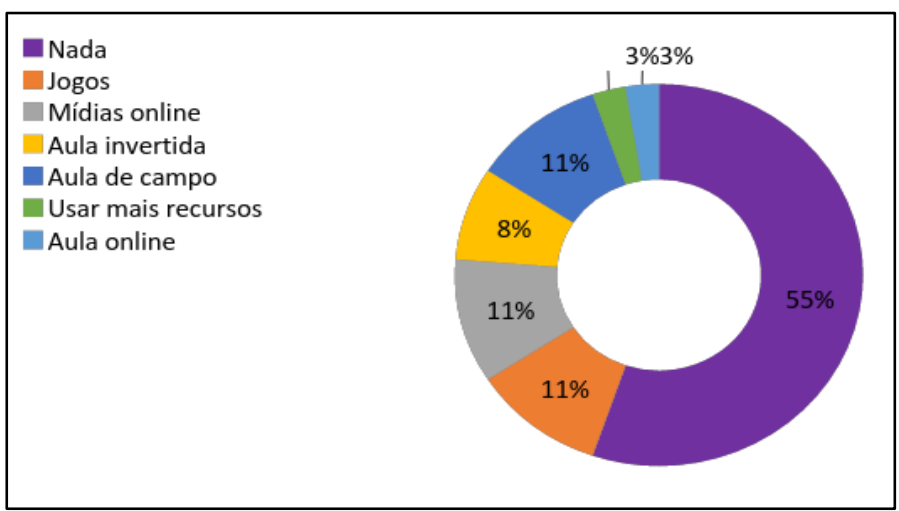

Fonte: Produzido pelos autores (2020).

Dentre as sugestões para o uso de outros/novos recursos didáticos, $10 \%$ sugeriram usar jogos; $10 \%$ propuseram fazer o uso de mídias online (redes sociais, aplicativos); $8 \%$ optaram por propor aula invertida (maior participação dos alunos); 11\% sugeriram aulas de campo; 3\% indicaram um maior uso dos recursos já utilizados; $3 \%$ aula online (em casa); e 55\% tiveram nada como sugestão para o melhoramento do uso do software educativo como recurso auxiliador do processo de ensino-aprendizagem.

\section{CONSIDERAÇÕES FINAIS: SEMPRE PROVISÓRIAS}

O desenvolvimento do presente estudo possibilitou uma análise comparativa das perspectivas dos alunos e da docente em relação à utilização de diferentes recursos didáticos. Além disso, também permitiu identificar os benefícios e dificuldades apontadas pelos discentes, pela professora e nas observações das aulas, que serviram para montar uma visão inicial que poderá contribuir para uma melhor adequação metodológica quanto ao uso desses recursos.

Com base nos dados advindos dos questionários com questões abertas aos alunos e das entrevistas com a docente, nos quais a utilização do quadro é apontada como prática em relação ao registro dos processos é visível por todos na construção das etapas de resolução dos cálculos. Além disso, a videoaula foi apontada como um recurso didático interessante pela contextualização com aspectos do cotidiano e pela disponibilidade de muitos desses materiais online (como na $\mathrm{EaD}$ ), bem como os slides, por serem uma apresentação eletrônica que engloba resumidamente conteúdos em tópicos e pelo uso de diferentes fatores (como o audiovisual), e o software educativo por usar uma metodologia de resolução de problemas (que é interessante na Matemática) e por integrar os alunos ao recurso que os faz participarem ativamente na construção dos conhecimentos. As dificuldades encontradas no uso desses recursos foram: o quadro em relação à dificuldade de 
enxergar; a escolha do material da videoaula e apresentação eletrônica; e o software educativo por problema de acesso à internet.

Considerando a importância do assunto, torna-se necessário o estudo e desenvolvimento de metodologias de ensino que possibilitem a utilização de múltiplos recursos didáticos, podendo aproveitar as potencialidades das ferramentas já utilizadas e das novas possibilidades dos novos recursos.

Nesse sentido, a utilização conjunta de diferentes recursos permite uma diversidade de métodos e técnicas que, se integrados, corroboram para uma maior eficiência em relação a alcançar os objetivos de ensino. Além disso, traz novas perspectivas do uso dos recursos didáticos para os licenciandos na formação inicial, potencializando o estudo sobre a perspectiva do ensino híbrido, além de fomentar uma reflexão sobre as múltiplas possibilidades que cada modalidade de ensino pode trazer para o aperfeiçoamento do ensino e da aprendizagem.

\section{REFERÊNCIAS}

ARAÚJO, J. C. S. Entre o quadro-negro e a lousa virtual: permanências e expectativas. In: Anais da Reunião Anual da Associação Nacional de Pós-Graduação e Pesquisa em Educação, p. 29-4, 2006.

BACICH, Lilian; TANZI NETO, Adolfo. A formação e a prática docente com o uso das tecnologias digitais: uma proposta de ensino híbrido. [S.l.:s.n]. Disponível em: https://www.researchgate.net/profile/Adolfo_Tanzi_Neto/publication/290597386_A_formacao_ e_a_pratica_docente_com_o_uso_das_tecnologias_digitais_uma_proposta_de_Ensino_Hibrido/l inks/5874a84008ae6eb871c96af7/A-formacao-e-a-pratica-docente-com-o-uso-das-tecnologiasdigitais-uma-proposta-de-Ensino-Hibrido $+\& \mathrm{~cd}=4 \& \mathrm{hl}=\mathrm{pt}-\mathrm{BR} \& \mathrm{ct}=\mathrm{clnk} \& \mathrm{gl}=\mathrm{br}$. Acesso em: 19 nov. 2019.

CANDEIAS, Cezar Nonato Bezerra; CARVALHO, Luis Henrique Pereira de. O uso de vídeoaulas como ferramenta no processo de ensino e aprendizagem em química. [S.1.:s.n], 2016. Disponível em: https://eventos.set.edu.br/index.php/simeduc/article/ download/3306/1234. Acesso em: 03 dez. 2019.

CHRISTESEN, Clayton; HORN, Michael; STAKER, Heather. Ensino híbrido: uma Inovação Disruptiva?. [S.1.]: Clayton Christensen Institute, 2015. 43 p.

FIDALGO, Fernando; MACHADO, Lucília (ed.). Dicionário da educação profissional. Belo Horizonte, MG: Núcleo de Estudos sobre Trabalho e Educação, FAE/UFMG, 2000.

GERHARDT, Tatiana Engel; SILVEIRA, Denise Tolfo. Métodos de pesquisa. Porto Alegre: Editora da UFRGS, 2009. 
GOUVÊA, Antônio Emilson Souza; PEREIRA, Elson de Menezes. O uso de tecnologia móvel: celular como apoio pedagógico na escola. In: II Colóquio de Letras da FALE/CUMB Formação de Professores: ensino, pesquisa, teoria, 2015. p. 41 - 55.

HOUAISS. Dicionário Eletrônico da Língua Portuguesa. Rio de Janeiro, RJ: Editora Objetiva, 2001.

JUCÁ, Sandro César Silveira. A relevância dos softwares educativos na educação profissional. Fortaleza, CE: Ciências \& Cognição, 2006.

LIBÂNEO, José Carlos. Didática. São Paulo: Cortez, 2015.

MORGADO, J. C. O estudo de caso na investigação em educação. Santo Tirso, Portugal: De Facto Editores, 2012.

PFROMM NETTO, Samuel. Tecnologia da educação e comunicação de massa. São Paulo: Pioneira, 1976.

RAMOS, Edla Maria Faust; ARRIADA, Mônica Carapeços; FIORENTINI, Leda Maria Rangearo. Introdução à educação digital: Guia do Cursista. 2. ed. Brasília, DF: Ministério da Educação, Secretaria de Educação à distância, 2009.

VEIGA, I. P. A. Apresentação. In: VEIGA, I. P. A. (Orgs.). Técnicas de ensino: novos tempos, novas configurações. Campinas: Papirus, 2016.

VYGOTSKY, L.S. A formação social da mente. São Paulo: Martins Fontes, 1994. 